Revue d'histoire de l'Amérique française

REYUE D.HISTOIRE DE L'AMÉRIQUE FRANÇAISE

\title{
BACKHOUSE, Constance et David FLAHERTY, eds., Challenging Times. The Women's Movement in Canada and the United States. Montréal, McGill-Queen's University Press, 1992. 335 p. $19,95 \$$
}

\section{Ellen Jacobs}

Volume 47, numéro 3, hiver 1994

URI : https://id.erudit.org/iderudit/305247ar

DOI : https://doi.org/10.7202/305247ar

Aller au sommaire du numéro

Éditeur(s)

Institut d'histoire de l'Amérique française

ISSN

0035-2357 (imprimé)

1492-1383 (numérique)

Découvrir la revue

Citer ce compte rendu

Jacobs, E. (1994). Compte rendu de [BACKHOUSE, Constance et David FLAHERTY, eds., Challenging Times. The Women's Movement in Canada and the United States. Montréal, McGill-Queen's University Press, 1992. 335 p. 19,95 \$]. Revue d'histoire de l'Amérique française, 47(3), 409-411.

https://doi.org/10.7202/305247ar d'utilisation que vous pouvez consulter en ligne. 


\section{COMPTES RENDUS}

BACKHOUSE, Constance et David FLAHERTY, eds., Challenging Times. The Women's Movement in Canada and the United States. Montréal, McGill-Queen's University Press, 1992. 335 p. 19,95\$

Toutes les auteures des textes de ce recueil ont participé, en mai 1989, à l'Université de Western Ontario, à un colloque qui portait sur l'analyse comparative du mouvement des femmes contemporaines au Canada et aux États-Unis. Le recueil reflète donc les forces et les faiblesses de la formule: il est intéressant de voir les participantes entamer un dialogue entre elles, mais certaines voix sont cependant absentes, notamment celles des femmes des Premières nations, des lesbiennes et des femmes handicapées. Certaines participantes semblent nager à contre-courant. Dans deux excellents essais fort pertinents qui semblent représenter le mouvement des femmes au Québec, Micheline Dumont, historienne à l'Université de Sherbrooke, et Micheline de Sève, professeure de science politique à l'Université du Québec à Montréal, traitent des aspects historiques et contemporains du mouvement des femmes au Québec, tout en essayant de réagir à de fausses interprétations flagrantes énoncées par d'autres conférencières au sujet des alliances féministes et nationalistes des Québécoises. En effet, les analyses comparatives sont faites dans la perspective Canada-États-Unis, et les comparaisons les plus réussies se trouvent dans les parties portant sur les revendications historiques et juridiques du mouvement des femmes.

Le recueil comporte huit parties dont chacune paraît correspondre à une séance du colloque. La première comprend quatre articles très intéressants sur les origines du mouvement des femmes contemporain au Canada et aux États-Unis. Jill Vickers discute des origines théoriques du mouvement des femmes au Canada; Sara Evans traite du mouvement des femmes aux ÉtatsUnis dans les années 1960; Micheline Dumont aborde les origines du mouvement des femmes au Québec. Dans un autre texte, Monique Bégin fait un retour sur le travail de la Commission royale d'enquête sur la situation de la femme au Canada (1967-1970) au sein de laquelle elle a occupé le poste de secrétaire exécutive. Elle attire l'attention sur l'effet que la Commission a eu en faisant entendre la voix des femmes «ordinaires» qui, par le biais de diverses associations, ont témoigné aux audiences.

Vingt ans plus tard, Monique Bégin fait remarquer que si la Commission a été le porte-voix des préoccupations des ménagères, elle n'a pas su élaborer une théorie critique par laquelle on aurait pu évaluer l'importance 
économique du travail de reproduction et de production effectué par les femmes. Une telle analyse a été développée par des sociologues féministes universitaires au cours des années 1970 et 1980. Monique Bégin avance que la création de la Commission royale d'enquête marque une date dans l'histoire des femmes canadiennes et que cela distingue celle-ci du mouvement des femmes aux États-Unis, en ce sens que le travail de la Commission «played a key role in creating and accelerating the process of feminist evolution in Canadian women's associations» (p. 35).

Bien qu'il soit intéressant de voir une participante importante évaluer les répercussions de son travail, Monique Bégin ne soulève pas ce qui a été et demeure une préoccupation des féministes partout en Amérique du Nord, à savoir la relation entre les féministes et l'État. Une critique de cette relation suppose une analyse féministe radicale de la nature patriarcale de l'État dans l'exercice de ses pouvoirs législatif, judiciaire et exécutif, de même que la mise en question des préjugés de classe et des préjugés racistes qui soustendent l'élaboration et la mise en application des politiques d'assistance sociale. Au cours des dernières années, les féministes et les militantes et militants «queer» ont dénoncé clairement les mesures prises pour définir juridiquement, et par là contrôler, la sexualité, comme en témoigne leur slogan «Get your laws off my body».

Dans un essai qui fait réfléchir sur la relation entre féministes universitaires et féministes militantes, Lorraine Greaves propose qu'on établisse une «définition opérationnelle du mouvement des femmes» qui inclurait toutes celles qui ne sont pas présentes aux colloques universitaires. Mariana Valverde fait une critique brève mais mordante du racisme qui règne dans les milieux universitaires et dans les programmes d'études féministes. En faisant allusion à la recherche qu'elle a effectuée récemment sur les mouvements de pureté sociale et raciale qui existaient au Canada anglais au dix-neuvième siècle, Mariana Valverde discute de l'ethnocentrisme du féminisme blanc («the whiteness of white feminism») et de l'«anxiété eurocentrique» («eurocentric anxiety») sous-jacente aux analyses de la sexualité qui sont issues du féminisme blanc. Elle semble cependant ne pas se rendre compte qu'elle associe l'appartenance au groupe des blancs en tant que privilège avec la couleur de la peau plutôt qu'avec la construction sociale d'un groupe dominant. On comprend alors comment il est possible de continuer de construire un récit du féminisme canadien-anglais dans lequel toutes les autres sujettes coloniales sont submergées par la trame impérialiste du discours canadien.

Dans son essai sur les perspectives des féministes québécoises («The Perspectives of Quebec Feminists»), Micheline de Sève signale l'importance démesurée que des Canadiennes anglaises ont accordée au rassemblement des «Yvette» en 1980 dans leurs comptes rendus du mouvement des femmes au Québec, alors qu'elles ont passé sous silence le deuxième rassemblement, celui des femmes en faveur du «Oui» au référendum de 1980. Selon Micheline de Sève:

It is absolutely shocking that English-Canadian feminist scholars stated that Quebec feminists as a group were for the NO option, while this is 
far from clear for anybody familiar with Quebec politics. This is a very important point, because it reveals a deep misunderstanding of the structure of the Quebec feminist movement and how we are all involved in the political definition of who we are as women, as Quebecers, as political scientists, or whatever, in search of a global project of society. (p. 113)

Dans ce livre, Micheline de Sève et Micheline Dumont tentent courageusement de démontrer la construction du récit féministe canadien-anglais afin de présenter leur propre lecture de l'histoire des Québécoises.

Le contenu de ce livre révèle, tout comme son titre l'indique, que nous vivons effectivement les défis d'une époque exigeante. Les étudiantes et les étudiants d'histoire, de science politique, de sociologie, d'études des femmes et d'études féministes, entre autres, acquerront une meilleure compréhension des divers aspects du mouvement des femmes contemporain à la lecture de cet ouvrage à prix modique.

Département d'histoire

Université du Québec à Montréal

ELLEN JACOBS 